\title{
EL MODELO DE NEUTRALIDAD DE LA RED EN LA UNIÓN EUROPEA: ALCANCE Y CONTENIDO
}

\author{
MARGARITA ROBLES CARRILLO' \\ Universidad de Granada \\ mrobles@ugr.es
}

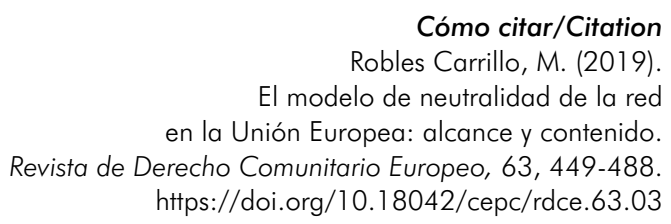

Resumen

El principio de neutralidad de la red es un componente esencial de la filosofía del ciberespacio. La neutralidad se ha explicado como el trato igualitario y no discriminatorio en el acceso y en el tráfico en internet. Pero este concepto es más complejo, más amplio y, también, más controvertido. La polémica sobre la neutralidad de la red se justifica por la existencia de diferentes conflictos de intereses y por el contenido evolutivo y la naturaleza transversal de este concepto. El estudio de su evolución y definición en el plano internacional y en el interno constituye un presupuesto previo y necesario para su consideración en el caso de la Unión Europea. En ese contexto, el análisis del principio de neutralidad comprende el estudio del marco estructural diseñado a través de la regulación europea, el marco normativo y el alcance y límites

1 Profesora titular de Derecho Internacional Público y Relaciones Internacionales. Miembro del Grupo Network Engineering \& Security (NESG-TIC233). Universidad de Granada. Este trabajo se realiza en el marco del Proyecto TIN2017-83494-R financiado parcialmente por el Gobierno de España. La última fecha de consulta de las fuentes electrónicas citadas ha tenido lugar el 1 de mayo de 2019. 
establecidos en sus disposiciones dentro del ámbito de las comunicaciones electrónicas. El modelo europeo no asume la naturaleza transversal de este principio, ni tampoco ofrece un concepto y un funcionamiento operativo acordes con la necesidad y la importancia de la neutralidad de la red.

\title{
Palabras Clave
}

Neutralidad de la red; concepto; naturaleza; modelo europeo.

\section{THE MODEL OF NETWORK NEUTRALITY IN THE EUROPEAN UNION: SCOPE AND CONTENT}

\begin{abstract}
The principle of network neutrality is an essential component of cyberspace philosophy. Neutrality has been explained as equal and non-discriminatory treatment in the access and traffic on the Internet. But this concept is more complex, broader and also more controversial. The discussion on network neutrality is motivated both by the existence of different conflicts of interest and by the evolutionary content and transversal nature of this concept. The study of its evolution and definition at the international and internal level is a prerequisite for its examination in the case of the European Union. In this context, the analysis of the principle of neutrality includes the study of the structural framework, the normative framework and the scope and limits established in the provisions in the area of electronic communications. The European model does not assume the cross-cutting nature of this principle, nor does it offer an operational and functional concept that matches the need and importance of network neutrality.
\end{abstract}

\section{Keywords}

Network neutrality; concept; nature; european model.

\section{LE MODÈLE DE NEUTRALITÉ DU RÉSEAU DANS L'UNION EUROPÉENNE: PORTÉE ET CONTENU}

\section{Résumé}

Le principe de neutralité du réseau est un élément essentiel de la philosophie du cyberespace. La neutralité a été expliquée comme un traitement égal et non discriminatoire en matière d'accès et de trafic sur Internet. Mais ce concept est plus complexe, plus large et aussi plus controversé. La discussion sur la neutralité du réseau est justifiée par l'existence de différents conflits d'intérêts et par le contenu évolutif et le 
caractère transversal de ce concept. L'étude de son évolution et de sa définition aux niveaux international et interne est une condition préalable à son examen dans le cas de l'Union européenne. Dans ce contexte, l'analyse du principe de neutralité comprend l'étude du cadre structurel conçu par la réglementation européenne, du cadre normatif et du champ d'application et des limites établies dans ses dispositions dans le domaine des communications électroniques. Le modèle européen n’assume pas la nature transversale de ce principe, pas plus qu'il n'offre un concept opérationnel et un fonctionnement à la mesure de la nécessité et de l'importance de la neutralité du réseau.

\section{Mots clés}

Neutralité du réseau; concept; nature; modèle européen. 


\section{SUMARIO}

I. INTRODUCCIÓN. II. EL CONCEPTO DE NEUTRALIDAD DE LA RED: 1. Contexto fáctico. 2. Evolución de la neutralidad de la red. 3. Contenido y naturaleza de la neutralidad de la red. III. EL PRINCIPIO DE NEUTRALIDAD DE LA RED: 1. Marco estructural: 1.1. EI ORECE. 1.2. Las ANR. 2. Marco normativo. 3. Alcance y límites de la neutralidad de la red: 3.1. Medidas de gestión del tráfico. 3.2. Excepciones. 3.3. Servicios especializados. IV. CONCLUSIONES. Biblografía.

\section{INTRODUCCIÓN}

El concepto de neutralidad de la red constituye un componente principal del ideario del ciberespacio y de internet. El origen de la neutralidad se remonta, sin embargo, mucho tiempo atrás porque está vinculado a la invención y el desarrollo de las comunicaciones electrónicas en las postrimerías del siglo XIX mediante el telégrafo y el teléfono (Morales y Pérez, 2015: 15-16) y a la definición de ciertos common carriage principles (Bauer, 2007:539). En su concepción básica consiste en garantizar un trato igualitario y no discriminatorio en la prestación de los servicios y respecto de los usuarios (González San Juan, 2016: 39). Pero la aplicación de este principio a la red supone un cambio sustancial no solo en cuanto al contexto en el que opera, sino también en su alcance, contenido, naturaleza y funcionamiento (Yemini, 2008: 35) ${ }^{2}$. La problemática que plantea es más amplia y compleja (Wu, 2004: 69). Por ello, no ha estado ni está exento de polémica (Bauer, 2007: 533).

El debate sobre la neutralidad de la red se está desarrollando en el plano interno y en el internacional, en el ámbito público y en el sector privado, con una activa participación del mundo empresarial, la industria, la academia y la sociedad civil a través de diferentes asociaciones y foros. Lejos de perder interés o actualidad, se reactiva continuamente, bien como consecuencia de

2 Sobre el funcionamiento de la neutralidad desde una perspectiva técnica básica, puede verse: Pisanty y Huesca (2015: 3-11); Bauer (2007: 533-537), y Morales y Pérez (2015: 8-15). 
las políticas adoptadas por algunos países promoviendo ${ }^{3}$ o restringiendo ${ }^{4}$, según los casos, el alcance de este principio, bien como respuesta a medidas técnicas o comerciales adoptadas por los proveedores de servicios de acceso a internet (PSI) (Carter et al., 2008: 2) o por los proveedores de servicios de aplicaciones y contenidos (PAC) (Ma y Misra, 2013: 1866).

Más allá de las divergencias entre los sujetos o los intereses en presencia (Ly et al., 2012: 3; Carter et al, 2008: 11) , que son naturales, hay un problema conceptual que se extiende desde la noción misma de neutralidad hasta su desarrollo en la práctica (Pisanty y Huesca, 2015: 2), donde concita un doble fenómeno. Por una parte, bajo la aparente cobertura de la neutralidad se adoptan medidas que difícilmente encajan dentro de ese concepto, por sí mismas o porque recogen más excepciones que reglas (González San Juan, 2016: 43). Mientras, por otra parte, se recurre a nociones y principios diferentes para designar contenidos normativos que responden a la concepción generalizada de neutralidad ${ }^{6}$. En el primer caso, la apología del concepto importa más que su contenido o su realidad. Entretanto, en el segundo, se advierte un rechazo al mismo no siempre comprensible o justificado. Ambos han conducido a vaciar de contenido u oscurecer el significado de la neutralidad de la red (Peha, 2006: 1), que, con frecuencia, se defiende o rechaza con más vehemencia que argumentos (Zhu, 2007: 644).

En general, se aprecia una falta de entendimiento en términos conceptuales y metodológicos y un discurso predefinido a favor o en contra de la neutralidad, con un fuerte componente axiológico, que condiciona y limita el alcance mismo del debate (Morales y Pérez, 2015: 108; Ly et al., 2012: 5). No es algo extraño, ni criticable por sí mismo. El discurso de la neutralidad de la red es un debate sobre valores y sobre la prioridad que se otorga a cada uno de ellos y es, también, un debate sobre intereses políticos (Zhu, 2007: 631), sociales (Cheng et al., 2012: 3), culturales (UNESCO, 2015; 19) y económicos (Schewick, 2005), con una pluralidad y diversidad de actores (Yoo, 2005: 13) y en un contexto marcado por la reducción de las asimetrías entre agentes estatales y no estatales en términos de poder y de influencia.

3 Es el caso de la India, donde, en 2017, se adoptan las «Recomendaciones sobre neutralidad de la red». Disponible en: https://bit.ly/2KouGK0

4 El caso paradigmático es la adopción de la Restoring Freedom Internet Order, en 2017, en EE. UU. Disponible en: https://bit.ly/2E7zXIL

5 Un estudio muy interesante sobre los casos relevantes y los intereses en presencia en la jurisprudencia norteamericana en materia de neutralidad puede verse en Morales y Pérez (2015: 36 y ss.).

6 Es el caso del recurso al concepto de internet abierta o la diferenciación entre dos tipos de neutralidad: lite y positiva (Marsden, 2012: 26; Orozco Salgado, 2015: 94). 
Jurídicamente, la neutralidad de la red plantea dos problemas principales que atienden a su contenido y su naturaleza. Por una parte, el concepto ha sido definido siguiendo diferentes aproximaciones metodológicas, pero se encuentra generalmente identificado con la idea de trato igualitario y no discriminatorio en el acceso y en el tráfico en Internet. Ello plantea la necesidad de preguntarse sobre su relación con el principio de no discriminación y sobre la posibilidad o no de definirlo como una categoría jurídica autónoma, porque esas respuestas afectan a su articulación jurídica. Por otra parte, la neutralidad de la red ha sido objeto de consideración - $\mathrm{y}$, en su caso, de regulación-, principalmente, en el marco de las comunicaciones electrónicas, la competencia, el comercio electrónico, la sociedad de la información, los derechos de los consumidores y los derechos y libertades básicos de las personas. El enfoque adoptado desde cada una de esas perspectivas no es — y difícilmente puede ser - uniforme u homogéneo. Pero, en la mayoría de ellas, se identifica el mismo problema consistente en desconocer o soslayar la naturaleza transversal del principio de neutralidad de la red. Ello conduce a adoptar una construcción particularizada, sectorial y fragmentada, en lugar de operar mediante un enfoque integral y general de la neutralidad de la red. Al obviar la naturaleza transversal, el concepto no es uniforme, ni puede ser de aplicación general. Al operar con conceptos sectoriales, la naturaleza de la neutralidad acaba siendo indeterminada. Según la perspectiva, la neutralidad se define como un derecho, como una libertad, como un principio o como todo ello (Morales y Pérez, 2015: 18). La articulación jurídica de ese concepto no puede ser igual en todos y cada uno de esos supuestos ${ }^{7}$. La problemática que plantea esta situación se manifiesta tanto en la práctica internacional como interna.

En el plano internacional, las posiciones adoptadas sobre la neutralidad de la red en el marco de la ONU, la UIT, la OMC, la OCDE, la OSCE o el Consejo de Europa (Morales y Pérez, 2015: 75) responden a parámetros diferentes $y$, a veces, hasta contradictorios ${ }^{8}$. En el plano interno, las modalidades de regulación de la neutralidad muestran una panorámica que va desde el rechazo mismo a su defensa a ultranza. La adopción de la Restoring Freedom

\footnotetext{
Pisanty y Huesca analizan diferentes enfoques regulatorios de la neutralidad con distintos resultados: el principio técnico, el enfoque centrado en el consumidor, el enfoque del ciudadano, el enfoque en términos de competencia y el marco regulatorio de las comunicaciones electrónicas (Pisanty y Huesca, 2015: 9-11; Marsden, 2012: 29).

8 Las diferencias regionales en el tratamiento de la neutralidad responden generalmente a opciones políticas y económicas y comerciales. Bauer (2007: 544); Sluijs (2010: 87); Morales y Pérez (2015: 15), y Carter et al. (2008: 3).
} 
Internet Order $^{9}$, en 2017, en EE. UU. se interpreta como la revocación de este principio y evidencia un polémico cambio de rumbo en la política seguida por este país ${ }^{10}$. Mientras, ese mismo año, la declaración de la no conformidad con el derecho europeo de la normativa neerlandesa sobre neutralidad por parte de un tribunal neerlandés es considerada un retroceso inquietante en el país adalid de la protección de la neutralidad de la red dentro de la UE ${ }^{11}$.

El propósito de este trabajo es analizar el principio de neutralidad de la red en el marco de la UE con el objetivo de determinar si esta organización ha dado respuesta a los problemas conceptuales y funcionales que plantea la neutralidad o si la acción europea está también estigmatizada por la problemática de fondo que plantea dicho principio. No se trata solo de una cuestión de orden teórico.

La pertinencia, el interés y la actualidad de este tema se justifican por cuatro motivos principales. El primero es la adopción, en diciembre de 2018, de la Directiva 2018/1972 por la que se establece el Código Europeo de Comunicaciones Electrónicas y del Reglamento 2018/1971, que es el nuevo marco jurídico del Organismo de Reguladores Europeos de las Comunicaciones Electrónicas (ORECE), autor de las directrices sobre neutralidad y referente principal en la aplicación de esta categoría dentro de la $\mathrm{UE}^{12}$. El segundo motivo es la cláusula de revisión contenida en el art. 9 del Reglamento 2015/2120, de 25 de noviembre de 2015, por el que se establecen medidas en relación con el acceso a una internet abierta y donde se incluyen los contenidos normativos materiales de la neutralidad, porque dispone que, a más tardar el 30 de abril de 2019, la Comisión revisará los arts. 3 a 6 del reglamento y procederá a informar al Parlamento Europeo y al Consejo con las propuestas adecuadas con vistas a modificar dicho reglamento. Un tercer motivo radica en que se están produciendo cambios fuera y dentro de la UE y, particularmente, en algunos Estados miembros que están desarrollando sus

9 Disponible en:https://bit.ly/2IphMKJ

10 En el informe presentado en el marco de la OMC de conformidad con el párr. G del mandato del Mecanismo de Examen de las Políticas Comerciales, a finales de octubre de 2018, se reconoce expresamente que se trata de una «revocación de la neutralidad de la red» (TPR/OV/21, 27 de noviembre de 2018, pg. 244). Doctrinalmente, se considera que, con esta medida, EE. UU. estaría vulnerando los compromisos asumidos en el marco del Cuarto Protocolo Anexo al GATS (Manner y Hernández, 2014: 73; Rodríguez y Carboni, 2015: 9).

11 Véase https://bit.ly/2QGFqVx.

12 El ORECE adopta las directrices sobre la aplicación de las normas europeas de neutralidad de la red por parte de las autoridades nacionales de reglamentación (BEREC, 2016). Disponible en: https://bit.ly/2JPtBLS. 
propias reglas en materia de neutralidad, mientras que no ocurre igual en otros o no se realiza en la misma dirección ${ }^{13}$. Para terminar, no en orden de importancia, prácticamente tres años después de su adopción, se han planteado ante el TJUE dos cuestiones prejudiciales relativas al alcance del art. 3 del Reglamento 2015/2120, la compatibilidad con el mismo de acuerdos comerciales zero-rating y la necesidad o no de realizar una evaluación de mercado y de impacto para determinar la existencia o no de una discriminación contraria a aquella disposición ${ }^{14}$.

Atendiendo al propósito indicado en el párrafo que precede a este último, en este trabajo se considera, primero, el concepto mismo de neutralidad de la red identificando el contexto fáctico en el que opera, su evolución, contenido y naturaleza. A continuación, se analiza la regulación de este principio atendiendo a su modelo estructural de aplicación, al marco normativo y a las excepciones y limitaciones incluidas en el mismo para terminar con unas conclusiones críticas. El principio de neutralidad de la red necesita un régimen jurídico uniforme y el reconocimiento de su naturaleza horizontal y transversal. Lejos de permanecer anclada en sus orígenes —el régimen de las comunicaciones electrónicas-, como ocurre siguiendo la normativa europea, hay que reconocer que la neutralidad afecta a las reglas de competencia (BEREC, 2012b: 34), al derecho de consumidores (Sidak, 2006: 350), al funcionamiento de la sociedad de la información (BEREC, 2015: 16) y, en general, a diversos componentes de la organización del mercado único digital. Pero afecta, también y especialmente, al contenido y al ejercicio de derechos y libertades básicas (Barata, 2012: 4), como la privacidad, la confidencialidad de las comunicaciones, la protección de datos personales, el derecho a la igualdad de trato o el principio de no discriminación, que es un fundamento básico del sistema europeo en su conjunto. Evitar la fragmentación del mercado interior y salvaguardar ese conjunto de derechos y libertades, con la coherencia que exige la naturaleza de este modelo de organización, son razones poderosas para

13 Sin ir más lejos, el art. 80 de la Ley Orgánica 3/2018 de 5 de diciembre, de protección de datos personales y garantía de los derechos digitales reconoce el derecho a la neutralidad de la red, pero el contenido de esa disposición no coincide con el prescrito por la normativa europea.

14 Se trata de los recursos planteados en los asuntos C-807/18 y C-39/19 por el Fovárosi Törvényszék húngaro. La solución jurisprudencial del TJUE es especialmente necesaria después de los pronunciamientos de órganos nacionales interpretando el alcance de la prohibición de discriminación como ocurre en el caso neerlandés. Para una evaluación de la práctica nacional puede verse The Net Neutrality Situation in the EU: Evaluation of the First Two Years of Enforcement. Disponible en: https://bit. ly/2Kokxgz. 
plantear el debate sobre la neutralidad en términos reales y precisos dentro de la UE.

\section{EL CONCEPTO DE NEUTRALIDAD DE LA RED}

La doctrina sobre el concepto de neutralidad es tan abundante como controvertida tanto en los aspectos jurídicos como en los tecnológicos. En el caso de los primeros se ha llegado a negar su existencia, en unas ocasiones por el contenido de su regulación y en otras porque, establecido el principio, se amplifican sus excepciones ${ }^{15}$. En relación con los segundos, hay un respetable sector doctrinal que excluye la posibilidad misma de garantizar desde una perspectiva técnica la neutralidad de la red (Zhu, 2007: 615; Pisanty y Huesca, 2015: 2 y 8) o que la cuestiona defendiendo la necesidad de sustituirla por categorías diferentes como los conceptos de Network Diversity (Yoo, 2005: 57) o Commodity Network (Beard et al., 2007: 153). Para abordar el problema conceptual, es conveniente realizar un apunte previo, necesariamente breve, sobre la estructura de internet desde una perspectiva técnica y sobre los conflictos de intereses que presiden el contexto fáctico en el que opera la neutralidad de la red.

\section{EL CONTEXTO FÁCTICO}

La arquitectura técnica de internet puede dividirse en dos partes claramente diferenciadas: la red de acceso, que permite a los usuarios conectarse, y la red troncal o núcleo, que sirve para trasladar la información de un lado a otro. El modelo estructural y funcional permite identificar cuatro capas: la capa física de los medios de transmisión; la capa lógica de los equipos que reciben o envían la información; la capa de direccionamiento lógico, enrutamiento y verificación sobre la disponibilidad de los dispositivos situados en los extremos de la red de acceso entre los que se transmite esa información; y la capa de control de las comunicaciones y aplicaciones, donde se encuentran los protocolos que controlan la comunicación siguiendo el principio end-to-end, en particular, el Internet Protocol (IP) y el Transmission Control Protocol (TCP) (Pisanty y Huesca, 2015: 3-5). La función de los PSI es básica en todo el proceso, desde el acceso mismo y el tráfico entre la IP de origen y la de destino, hasta la creación y mantenimiento de las infraestructuras que

15 La doctrina ha identificado dos escuelas de pensamiento principales: opennist y deregulationist (Wu, 2004: 71-79; Schewick, 2005). 
permiten la comunicación, mientras que los PAC, conocidos también como OTT (Over the Top) porque operan sobre la red y no dentro de ella, se sitúan en los extremos, suministrando aplicaciones y servicios.

La comunicación dentro de la red se realiza mediante mensajes construidos a esos efectos en los que se distingue la llamada carga útil (Payload), donde está el contenido que son los datos de comunicación, y la cabecera (Header), que indica las IP de origen y de destino, que son los datos de tráfico. El acceso a los datos de tráfico permite la comunicación entre ambas IP. El acceso a los datos de comunicación, al contenido material de la comunicación realizada, aunque es posible mediante técnicas de inspección profunda (Deep Packet Inspection) basadas en distintas modalidades de análisis, es contrario a derechos como la privacidad, la confidencialidad de las comunicaciones y la protección de datos personales. El conocimiento de esos datos, incluso simplemente los de tráfico, puede ser usado para privilegiar o para obstaculizar el acceso y el tráfico en la red. Cabría, en consecuencia, la posibilidad de que, por las razones que fuese, y entre ellas el pago de algún tipo de tarifa o contraprestación económica, determinados usuarios se beneficiasen de un acceso más rápido o un tráfico priorizado en perjuicio de otros. Esa posibilidad de discriminar entre usuarios, limitando la capacidad de uso de internet por motivos económicos o de otra índole, es contraria a la idea básica de accesibilidad universal y la concepción del acceso a Internet como un derecho universal. La neutralidad se justifica por la necesidad de evitar esa discriminación entre usuarios, pero no está formalizada en todos los ordenamientos jurídicos, aunque sí mayoritariamente. El problema adicional estriba en que, dado que el tráfico se realiza a través de la interconexión de numerosos operadores que pueden estar localizados en países distintos con regímenes jurídicos diferentes, garantizar la neutralidad conforme a la legislación de un Estado no implica garantizar efectivamente la neutralidad si el tráfico se realiza a través de servidores situados en países en los que no se contempla dicho principio. La regulación no es fácil por la existencia de intereses divergentes.

Los conflictos de intereses abundan en la red entre distintas categorías de sujetos, pero el núcleo principal de controversia se localiza entre los PSI y los PAC. La razón es tan sencilla como compleja resulta su solución. Los PSI, proveedores de comunicaciones electrónicas como operadores de redes o compañías telefónicas, se ocupan del sostenimiento y funcionamiento de las redes, están sujetos a un estricto y complejo régimen jurídico y obligados a realizar altas inversiones con una escasa rentabilidad a corto o medio plazo para el mantenimiento y desarrollo de las infraestructuras necesarias para el acceso y la comunicación a través de internet. Los PAC no cumplen una función dentro de la red, no están sometidos a un régimen jurídico como el 
de los PSI, usan esas infraestructuras sin inversión y cuentan con ingresos y beneficios derivados de la explotación de las aplicaciones y servicios que suministran, la publicidad o cualesquiera otras modalidades de negocio.

El crecimiento exponencial de los usuarios, aplicaciones y servicios convierte en ineludible y constante la necesidad de articular infraestructuras y sistemas capaces de soportar un tráfico mayor y más denso. Esa obligación recae fundamentalmente en los PSI mientras que son los PAC sus principales beneficiarios. Las obligaciones en materia de acceso abierto y neutralidad recaen también sobre los PSI. Los PAC se benefician de este principio, como lo haría un usuario individual, aunque apuestan por la exclusión del mismo si ello les permite obtener un trato privilegiado a cambio de una tarifa más alta que pueden asumir en mayor medida que un usuario individual. Pero si el acceso y el tráfico dependen de la capacidad económica de los usuarios, deja de ser un derecho para convertirse en sí mismo en una mercancía solo disponible para quienes puedan pagarla. La neutralidad se reconoce, por ello, como un derecho de los usuarios y una obligación a cargo fundamentalmente de los PSI, si bien el alcance y significado preciso de este concepto genera polémica.

La ausencia de un concepto técnico y/o jurídico consensuado y definitivo sobre la neutralidad de la red ha sido puesta de manifiesto en el plano institucional ${ }^{16}$ y doctrinal (Orozco Salgado, 2015: 91; Morales y Pérez, 2015: 27; Cheng et al., 2012). Esa situación se justifica ab initio por dos motivos principales: la naturaleza esencialmente evolutiva y el contenido potencialmente variable de la idea de neutralidad. El avance científico y tecnológico, imparable y difícilmente predecible (Frieden, 2015: 743), obliga a operar sobre una realidad en permanente mutación que altera las condiciones de implementación técnica de la neutralidad y mantiene abiertos y potencialmente variables los conflictos de intereses subyacentes a esta categoría (Zhu, 2007: 624). Esa constante inestabilidad, a la que contribuye además la transversalidad propia de la neutralidad, condiciona su naturaleza desde el punto de vista jurídico. El debate conceptual es prioritario (Wu y Yoo, 2007: 2). La evolución que ha conocido la idea de neutralidad de la red en términos jurídicos es el punto de partida a esos efectos (Zhu, 2007: 627-631).

16 El CESE explica que «la falta de definición explícita de los principales términos en cuestión representa un problema grave: sin definición no puede haber ni exposición de argumentos ni orientaciones claras para el mercado y los reguladores acerca del objetivo que persigue el Derecho europeo en esta materia» (Dictamen del Comité Económico y Social Europeo 2012/C 24/31, DO C 24, de 208 de enero de 2012, p. 140). OCDE (2011: 25; OCDE (2015:4) y Parlamento Europeo (2014). 


\section{EVOLUCIÓN DE LA NEUTRALIDAD DE LA RED}

El estudio de la normativa, la práctica y la doctrina ${ }^{17}$ permite identificar cuatro etapas principales en la definición de la neutralidad de la red dentro de un proceso caracterizado por una reducción progresiva de sus contenidos que afecta a la determinación de su naturaleza jurídica.

A) En un primer período, en los orígenes de la red, la neutralidad se concibe como una característica fundacional y definitoria de internet. La paternidad del concepto se atribuye a Tim Wu, para quien «Network neutrality is best defined as a network design principle» (Wu y Lessig, 2003) ${ }^{18}$. En realidad, la construcción apologética de la neutralidad característica de esa primera etapa es el resultado de una confluencia de visiones sobre el ciberespacio procedentes esencialmente de sus artífices, entre los que destacan Vint Cert y Tim Berners-Lee (Berners-Lee, 2010: 2) y antes, incluso, Marsden, Cooper, Lemley o Lessig (Belli y De Filippi, 2016: 22). En ese período, la neutralidad de la red es una categoría axiológica cuya principal funcionalidad reside en destacar la singularidad del mundo virtual respecto al físico. Asociada a un mundo utópico de libertades, su contenido y naturaleza resultan imprecisos o indefinidos desde una perspectiva jurídica, pero están claramente vinculados al marco conceptual de los derechos y libertades que forman parte del imaginario original del ciberespacio ${ }^{19} \mathrm{y}$ a la idea de participación democrática (Marsocci, 2017: 45).

B) La segunda etapa de esa evolución, en la primera década del siglo xxI, supone un cambio de paradigma en la medida en que la atención se desplaza hacia la articulación jurídica del concepto de neutralidad. Hay, no obstante, sectores de la empresa y la industria para quienes «any neutrality regulation is a solution looking for a problema» (Wu, 2004: 91).

En el marco de la UIT, se trabaja sobre una concepción amplia asumiendo los aspectos técnicos y primando la libertad y la calidad del acceso ${ }^{20}$. En 2005, en EE. UU., la Federal Communications Commission (FCC) adopta

17 No hay por el momento jurisprudencia del TJUE sobre el concepto de «neutralidad de la red», «internet abierta» o el Reglamento 2015/2120, aunque se hayan planteado entre finales de 2018 y principios de 2019 dos recursos. El principio de neutralidad tecnológica sí es objeto de análisis jurisprudencial.

18 Véase https://bit.ly/1jMiCi7.

19 En ese período, no obstante, en el marco regulador de las comunicaciones electrónicas adoptado en 2002 en la UE se incluyen principios relativos al acceso, con carácter general, pero no identificados con el concepto de neutralidad de la red (Carter et al, 2008: 43).

20 Véase https://bit.ly/2JSG1CQ. 
un Policy Statement definiendo los pilares de la neutralidad ${ }^{21}$ (Sluijs, 2010: 77). En 2010, la Open Internet Order se ocupa de ampliar esos contenidos ${ }^{22}$, asumiendo su impronta en derechos básicos, en particular la libertad de expresión (Yemini, 2008: 5). Entretanto, en Europa el proceso se desarrolla temporalmente en paralelo en el Consejo de Europa y en la UE, pero no en una misma dirección.

En el primer caso, el Comité de Ministros adopta una Declaración sobre la neutralidad de la red, el 29 de septiembre de 2010, en la que, sin desconocer otros aspectos, el bien jurídico protegido es la defensa de los derechos y libertades de información y de expresión ${ }^{23}$, mientras que el trato igualitario o no discriminatorio se concibe como un medio para garantizar aquellos derechos y libertades que constituyen el núcleo explicativo del principio de neutralidad $^{24}$. Doctrinalmente, An-Shou Cheng et al. (2012: 3) afirman que «this concept should include the general principles that owners of the networks that compose and provide access to the Internet should not control how consumers lawfully use that network». La introducción de la idea de ausencia de control supone incorporar un contenido nuevo jurídicamente relevante y adicional al trato igual y no discriminatorio, que se sitúa tanto en el terreno de los derechos y libertades básicos como en contexto normativo de la protección de consumidores.

En la UE, el marco donde se garantiza el carácter abierto y neutral de la red es la normativa reguladora de las comunicaciones electrónicas (Cullell March, 2011: 70) ${ }^{25}$. Pero el concepto de neutralidad de la red no resulta formalizado en la parte dispositiva de esa normativa, sino que se incorpora como anexo a la Directiva 2009/140 mediante una declaración de la

21 Estos pilares son: la libertad de acceso a contenidos, la libertad de ejecución de aplicaciones y servicios, la libertad de conexión de dispositivos y el derecho a la libre competencia entre proveedores de redes, servicios o aplicaciones y contenidos.

22 Incluye medidas dirigidas a garantizar la transparencia, prohibir el bloqueo de contenidos, aplicaciones, servicios o dispositivos y prohibir, asimismo, la discriminación no razonable del tráfico legal en la red. Pero resulta finalmente anulada en 2014 por falta de competencia de la FCC para su adopción.

23 La jurisprudencia del TEDH interpreta estos derechos en el contexto creado por la aparición de internet. Disponible en: https://bit.ly/2Kmc8dz.

24 Véase https://bit.ly/318r59d.

25 En el contexto de la reforma de 2009, el art. 8.4.g de la Directiva 2009/140/CE establece la obligación de las ANR de promover la capacidad de los usuarios finales para acceder al contenido, las aplicaciones o los servicios de su elección (DO L 337, de 18 de diciembre de 2009, p. 51). Ese objetivo se refuerza en algunas disposiciones de la Directiva 2009/136/CE (DO L 337, de 18 de diciembre de 2009, pp. 24-25). 
Comisión ${ }^{26}$. Además de quedar plasmada solo como objetivo político y como principio regulador de la acción de las autoridades nacionales de reglamentación (ANR), no se asocia a los fundamentos constitutivos del proceso, ni se reconoce su carácter transversal ${ }^{27}$.

C) La tercera etapa se caracteriza por la asociación de los conceptos de internet abierta y neutralidad. Generalmente, no se aclara el significado de cada uno de esos conceptos (Wu, 2005: 145) o se utiliza indistintamente (OCDE, 2015: 15; UNESCO, 2015: 10; Belli y Bergen, 2013: 12). Tim Wu recurre al concepto de Internet Freedom, que implica «freedom to access content, freedom to use applications, freedom to attach personal decives and freedom to obtain service plan information». En su Draft Network Neutrality Rules, el autor identifica la neutralidad como «a general right to unrestricted network usage» (Wu, 2004: 95). Para la American Civil Liberties Union, «the freedom and openness of the Internet was protected by rules of "net-work neutrality» (ACLU, 2013: 1). Una idea similar — que identifica la neutralidad como el medio para garantizar un internet abierto - se encuentra en las Directrices sobre Neutralidad de la Red adoptadas en 2009 en Noruega ${ }^{28}$. En esa línea, la Comisión explica que la esencia de este concepto atiende a la mejor manera de mantener la apertura de la red, reconociendo la posible afectación de derechos y libertades, pero sin avanzar en su definición a nivel europeo ${ }^{29}$. El Parlamento Europeo alterna los conceptos de internet abierta y neutralidad ${ }^{30}$. Mientras, en sus conclusiones al respecto, el Consejo mantiene la definición de la neutralidad como un objetivo político situado en el marco regulador de las comunicaciones electrónicas instando a los Estados miembros a fomentar su aplicación y a garantizar el carácter abierto y neutral de Internet ${ }^{31}$.

26 En ella, la Comisión «otorga gran importancia al mantenimiento del carácter abierto y neutral de Internet, teniendo plenamente en cuenta la voluntad de los colegisladores de consagrar ahora la neutralidad de Internet como un objetivo político y un principio regulador que han de ser fomentados por las autoridades nacionales de reglamentación» (DO L 337, de 18 de diciembre de 2009, p. 69). El debate interinstitucional muestra el alcance de la polémica en torno a este concepto (Sluijs, 2010: 98).

27 Así se muestra, en el marco de la Agenda Digital Europea, en la Declaración Ministerial de Granada, de 19 de abril de 2010.

28 «Network neutrality Guidelines for Internet neutrality». Véase https://bit.ly/2QBFRju.

29 Comunicación de la Comisión al Parlamento Europeo, al Consejo, al Comité Económico y Social Europeo y al Comité de las Regiones, de 19 de abril de 2011, sobre la internet abierta y la neutralidad de la red en Europa, COM(2011) 0222.

30 Véase https://bit.ly/2HS5Lgp.

31 Véase https://bit.ly/2MnLtQ8. 
La calificación como objetivo político y la adscripción a ese marco normativo supone asestar un doble golpe a la neutralidad. Desde el punto de vista de su naturaleza, es difícil entender cómo un principio que traduce el derecho de los usuarios y la obligación de los PSI de garantizar un trato igualitario y no discriminatorio puede definirse como objetivo político cuando el principio de no discriminación es un principio constitutivo y un derecho esencial en el marco de la UE, salvo que la neutralidad signifique algo más que eso y, por ello, deba mantener ese estatuto en lugar de formalizarse jurídicamente. Desde el punto de vista de su contenido, la acotación de la neutralidad al marco regulador de las comunicaciones electrónicas traduce una visión formalista, que soslaya su naturaleza horizontal y transversal, anclada en los orígenes del concepto e incapaz de trasladar la reformulación conceptual y funcional que requiere su aplicación como principio a la red. La neutralidad de las comunicaciones del siglo XIX poco tiene que ver con la neutralidad de la red del siglo XxI.

En su dictamen sobre la comunicación de la Comisión, el Comité Económico y Social Europeo (CESE) marca un punto de inflexión en una doble dirección. Por una parte, defiende la consagración de los conceptos de internet abierta y de neutralidad de la red adoptando un enfoque proactivo en el que la neutralidad se confirma como un objetivo político y un principio jurídico ${ }^{32}$. Por otra parte, diferencia y explica los conceptos de internet abierta ${ }^{33}$ y de neutralidad. Mientras la internet abierta se vincula a la libertad de conectarse y de utilizar internet, la neutralidad de la red se sitúa en el marco de la relación comercial entre usuarios y PSI. No obstante, esa diferenciación despoja a este concepto del importante significado axiológico que tiene impreso en su definición desde su formulación en el marco del ciberespacio.

D) La cuarta etapa supone la consolidación de la preeminencia del concepto de internet abierta ${ }^{34}$ y una cierta desnaturalización de la idea de

32 Véase https://bit.ly/2KoIAMy.

33 Según el CESE, el concepto de internet abierta encierra un triple significado: a) la idea de que su contenido está a disposición de cualquier persona con conexión a la red; b) el hecho de que utiliza estándares libres y públicamente disponibles a los que cualquiera tiene la posibilidad de recurrir para crear contenidos, aplicaciones o servicios; y c) el principio de que los usuarios son libres de conectarse a la Internet pública sin restricciones por parte de gobiernos o PSI en relación con los contenidos, sitios, plataformas o tipos de equipos o las modalidades de comunicación (DO C 24, 28 de enero de 2012, pp. 140-141).

34 El recurso a la expresión «internet abierta», como alternativa a la neutralidad, se ha justificado en algún sector doctrinal (Pisanty y Huesca, 2015: 2) y en el plano institucional (OCDE, 2011: 6). 
neutralidad por su limitación al trato equitativo y no discriminatorio. En EE.UU. (Friedlander, 2016: 907), bajo el impulso de la presidencia de Obama $^{35}$, en 2015, la FCC adopta la Open Internet Order, donde la neutralidad se construye sobre la base de tres reglas: la imposibilidad de priorizar el tráfico a cambio de recompensas o compensación, la imposibilidad de bloquear el acceso por razones comerciales y la imposibilidad de restringir o degradar el tráfico por recompensas o remuneraciones (Frieden, 2015: 759) ${ }^{36}$. Esas reglas son finalmente revocadas en 2017 mediante la Restoring Freedom Internet Order (Gilroy, 2018: 10). Entretanto, en Europa, la idea de neutralidad se concreta por diferentes cauces.

En 2013, el Consejo de Europa había reconocido la naturaleza instrumental y el carácter transversal del principio de neutralidad, subrayando su función en el contexto de los derechos y libertades básicas (Belli y Bergen, 2013: 26). Pero, poco tiempo después, en la Recomendación CM/Rec (2016)1 del Comité de Ministros, el principio de neutralidad se define afirmando que «Internet traffic should be treate dequally, without discrimination, restriction or interference irrespective of the sender, receiver, content, application, service or device» ${ }^{37}$. En un apéndice de la recomendación se establecen las Directrices sobre Neutralidad de la Red. En ellas, este principio se sustenta en un doble componente: la idea de trato igualitario y no discriminatorio y el derecho a enviar y recibir información sin que pueda verse restringida mediante bloqueos, ralentización, degradación (BEREC, 2012a: 37) o discriminación del tráfico asociados a determinados servicios, aplicaciones o contenidos $^{38}$. Con posterioridad, en la Recomendación CM/Rec (2018)2 del Comité de Ministros sobre los roles y responsabilidades de los intermediarios de internet se refuerza el vínculo de este principio con el conjunto de derechos y libertades fundamentales recogidos en el $\mathrm{CEDH}^{39}$.

En la UE, la preferencia por el concepto de internet abierta y la asociación de la neutralidad con el trato equitativo y no discriminatorio se confirma con la adopción del Reglamento 2015/2120 (Marcus, 2016: 260). La Directiva 2018/1972

35 Véase https://bit.ly/2wwT0RU.

36 Véase https://bit.ly/1LPxNCr .

37 Recomendación CM/Rec (2016) 1 del Comité de Ministros sobre la protección y promoción del derecho a la libertad de expresión y el derecho a la vida privada en relación con la neutralidad de la red, de 13 de enero de 2016 (https://bit.ly/2ENVbVC).

38 Véase https://bit.ly/2ENVbVC.

39 Véase https://rm.coe.int/1680790e14.

40 Reglamento (UE) 2015/2120 del Parlamento Europeo y del Consejo, de 25 de noviembre de 2015, por el que se establecen medidas en relación con el acceso a una internet abierta y se modifica la Directiva 2002/22/CE relativa al servicio universal y 
del Parlamento Europeo y del Consejo, de 11 de diciembre de 2018, por la que se establece el Código Europeo de Comunicaciones Electrónicas mantiene esa opción ${ }^{41}$, al igual que el Reglamento 2018/1971, relativo al Organismo de Reguladores Europeos de las Comunicaciones Electrónicas (ORECE) ${ }^{42}$.

El análisis del Reglamento 2015/2120 permite llegar a tres conclusiones principales: 1) la confirmación del concepto de internet abierta asociado a la definición de los derechos de los usuarios finales y al principio de transparencia ${ }^{43}$; 2) el rechazo a la formalización jurídica del término neutralidad en un acto jurídicamente vinculante (Pisanty y Huesca, 2015: 18), a pesar de que es el empleado en la normativa de desarrollo adoptada por el ORECE (Morales y Pérez, 2015: 218); y 3) la concepción de la neutralidad asociada al trato equitativo y no discriminatorio y al marco regulador de las comunicaciones electrónicas, soslayando tanto su naturaleza transversal como su significado axiológico en el contexto de su aplicación al ciberespacio. El contenido y la naturaleza de este concepto no están definitivamente resueltos.

\section{CONTENIDO Y NATURALEZA DE LA NEUTRALIDAD DE LA RED}

Alejándose de su concepción primigenia, y como consecuencia de su progresiva definición normativa, la neutralidad parece quedar reducida al principio de trato igual o equitativo y no discriminatorio aplicado al acceso y al tráfico en la red (Peha et al., 2007: 711). Desde la perspectiva de su naturaleza jurídica, la situación no es la misma que cuando se define inicialmente y/o se mantiene en algunos sistemas jurídicos como un derecho, una libertad y un

los derechos de los usuarios en relación con las redes y los servicios de comunicaciones y el Reglamento (UE) 531/2012 relativo a la itinerancia en las redes públicas de comunicaciones móviles en la Unión (DO L 310, de 26 de noviembre de 2015, p. 1). DO L 321, de 17 de diciembre de 2018, p. 36. La directiva no menciona la neutralidad de la red, aunque sí el principio de neutralidad tecnológica.

42 Reglamento (UE) 2018/1971 del Parlamento Europeo y del Consejo, de 11 de diciembre de 2018, por el que se establecen el Organismo de Reguladores Europeos de las Comunicaciones Electrónicas (ORECE) y la Agencia de apoyo al ORECE (Oficina del ORECE), por el que se modifica el Reglamento (UE) 2015/2120 por el que se deroga el Reglamento (CE) 1211/2009 (DO L 321, de 17 de diciembre de 2018, p. 1).

43 La doctrina ha subrayado la importancia de asociar transparencia y neutralidad (Marsden, 2012: 31), así como ha sido ampliamente explicado por el BEREC (BEREC, 2011: 7-13). Este organismo considera que es necesario clarificar el requisito de transparencia en sus directrices sobre neutralidad (BEREC, 2018: 12). 
principio (Morales y Pérez, 2015: 54) ${ }^{44}$. Como primera providencia, el hecho de identificarla con el principio de no discriminación requiere la comprobación de la existencia de una diferencia de trato no justificada o un trato similar no justificado, lo que implica un sistema de garantía más complicado que cuando se trata de reconocer un derecho o una libertad sin modelos referenciados. En segundo término, ello supone alejar la definición de la neutralidad de la red de su calificación originaria como componente fundacional inscrito en la genética del ciberespacio para situarlo en un contexto conocido y gestionable jurídicamente, pero en el que pierde su significado axiológico original. En tercer lugar, se desvincula del ejercicio de derechos y libertades fundamentales como la expresión y la información y de otros ámbitos materiales en los que, jurídicamente, tiene cabida y justificación como ocurre en protección de consumidores (BEREC, 2015: 13), competencia (Greenstein et al., 2016: 19; Carter et al., 2008: 42), industria (Beard et al., 2007: 150), propiedad intelectual (Frieden, 2008; 634), el comercio electrónico o la sociedad de la información, que alimentan la naturaleza transversal de la neutralidad y fundamentan su componente axiológico (Marsden, 2012: 36), superando con creces el significado primigenio de ese concepto a finales del siglo XIX en el contexto de las comunicaciones electrónicas.

El problema de fondo que plantea la identificación entre neutralidad y trato equitativo y no discriminatorio es la justificación misma de la existencia de la neutralidad y su condición o no como categoría jurídica autónoma. Hay dos situaciones posibles. En la primera, en el supuesto de identidad entre ambos, el principio de no discriminación habría de ser suficiente para exigir y garantizar un trato igual y no discriminatorio en el acceso y en el tráfico en internet, en cuyo caso no estaría justificado el recurso al principio de neutralidad. En la segunda, el principio de no discriminación no sería suficiente para garantizar ese contenido dispositivo, razón por la cual se habría recurrido al concepto de neutralidad para garantizar un trato no discriminatorio en el acceso y en el tráfico dentro de la red. En cualquiera de los casos, no se entendería la limitación en cuanto a su naturaleza en el marco de la UE, al definirlo como objetivo político, cuando generalmente se asume como principio jurídico (Morales y Pérez, 2015: 54).

La cuestión puede plantearse en términos de necesidad y oportunidad. En caso de no haber sido necesario, porque era suficiente con el principio de

44 La neutralidad se ha definido como un derecho que comprende otros derechos: «1) the right to choose service providers, 2) the right to use the medium in order to access the internet, and 3) the right to use data and content, accessed equally through this medium» (Cheruvalath, 2018: 147). 
no discriminación, cabría preguntarse si esta operación de identificación del contenido de ambos podría estar destinada en mayor medida a desvirtuar el principio de neutralidad de la red, privándolo de su significado axiológico, que a tipificarlo. Por otro lado, en caso de haber sido necesario el recurso al concepto de neutralidad de la red, a pesar de la supuesta identidad de contenidos, cabría preguntarse si la necesidad de articular este principio trae causa de la dificultad que puede plantear la extrapolación del principio de no discriminación al acceso y tráfico en las redes o se justifica porque, en realidad, la neutralidad no es exactamente o exclusivamente un trato equitativo o igualitario (Cheruvalath, 2018: 150) y no discriminatorio aplicado en los mismos términos y con el mismo alcance y contenido que se atribuye al principio de no discriminación, esto es, no se trata simplemente de la versión de ese principio aplicada al ciberespacio (Bauer, 2007: 540).

En mi opinión, la neutralidad de la red cuenta con un alcance y un contenido propios, que resultan más amplios que el trato equitativo y no discriminatorio cuando se vinculan al contenido y al ejercicio de determinados derechos y libertades y, también, más restringidos o limitados cuando se establecen condiciones, excepciones o limitaciones a dicho principio motivadas por razones técnicas o jurídicas, que reducen el alcance de la prescripción de tratamiento no discriminatorio. La tendencia a equiparar ambos principios soslaya el hecho de que, incluso si se obvia su vinculación con el ejercicio de derechos y libertades fundamentales, como el derecho de expresión y la libertad de información, las excepciones y limitaciones derivadas de requerimientos técnicos y jurídicos que se establecen en materia de neutralidad de la red limitan su alcance y contenido y lo singularizan respecto del principio de no discriminación, abundando en la necesidad de definirlo como categoría autónoma.

La calificación de la neutralidad de la red como categoría autónoma se apoya, asimismo, en el análisis normativo. En las directrices adoptadas en 2009 en Noruega, la neutralidad se traduce en un conjunto de principios con un contenido más amplio porque comprende los derechos de acceso con una determinada capacidad y calidad, el derecho de conexión y el derecho de no discriminación en relación con aplicaciones, servicios y contenidos o sobre la base de las direcciones de envío o recepción ${ }^{45}$, aunque contempla excepciones justificadas por imperativos de gestión del tráfico, cumplimiento de órdenes de autoridades o necesidades de calidad o de prioridad del servicio en determinados supuestos. En las recomendaciones adoptadas en la India, en 2017,

45 Véase https://bit.ly/2QBFRju. 
la neutralidad representa los derechos de acceso y de no discriminación ${ }^{46}$, englobando también los primeros que, en cambio, en la normativa europea se asocian a la idea de internet abierta. Por otra parte, si se atiende a los trabajos de la Asamblea Parlamentaria del Consejo de Europa, la neutralidad viene definida sobre la base dos parámetros: "The obligation for internet Access providers to treat all content transmitted on the web equally and the possibility for internet users to view and freely disseminate content on the web» ${ }^{47}$.

Finalmente, en el Reglamento 2015/2120 y en las directrices del ORECE, la neutralidad constituye la suma de dos obligaciones ${ }^{48}$ : una, la obligación de tratar todo el tráfico de manera equitativa, sin discriminación, restricción o interferencia, con independencia del emisor y el receptor, el contenido, las aplicaciones o servicios o el equipo terminal empleado (art. 3.3, párr. 1. ${ }^{\circ}$ ); y dos, la obligación de no bloquear, ralentizar, alterar, restringir, interferir, degradar, ni discriminar entre contenidos, aplicaciones o servicios concretos o categorías específicas (art. 3.3, párr. 3. ${ }^{\circ}$ ). Ambas obligaciones, bajo la apariencia de similaridad, son diferentes por tres motivos: a) aunque los conceptos de discriminación, restricción e interferencia están presentes en ambas obligaciones, solo en la segunda se incluye "bloquear», «ralentizar», «alterar» o «degradar», por lo que, de darse estas circunstancias, se produciría una vulneración de la segunda obligación, pero no de la primera; b) mientras que en el párr. $10^{\circ}$ del art. 3.3 esas acciones están vinculadas al tratamiento del tráfico de manera equitativa y sin discriminación y requieren un análisis en términos de comparación — para determinar si se ha dado un trato similar a situaciones similares y diferente a situaciones desiguales o, por el contrario, no se ha dado-, en el párr. 2.0 están descritas con carácter general y solo se exigiría la comparación respecto del supuesto concreto de discriminación y no en relación con los demás; y c) la obligación recogida en el párr. $1 .^{\circ}$ tiene como posible excepción la adopción de medidas razonables de gestión del tráfico previstas en el párr. $2 .^{\circ}$, mientras que las denominadas oficialmente «excepciones» están adscritas a la obligación establecida en el párr. 3. ${ }^{\circ}$ del art. 3.3. Los servicios especializados constituirían una excepción respecto de ambas obligaciones.

En definitiva, el principio de neutralidad de la red constituye una categoría autónoma y diferente del principio de no discriminación en el marco de

46 Véase https://bit.ly/2KouGK0.

47 Resolución 2256 (2019), de 23 de enero de 2019. Disponible en: https://bit.ly/2JXlhd8.

48 Para Marsden, comprende dos compromisos de no discriminación diferentes: uno de servicio universal y otro de servicio público de transporte (Marsden, 2012: 26). 
la UE porque implica la obligación de trato equitativo y no discriminatorio en el acceso y en el tráfico a través de internet y la obligación de no bloquear, ralentizar, alterar, restringir, interferir, degradar, ni discriminar entre contenidos, aplicaciones o servicios concretos o categorías específicas excepto en los supuestos concretos establecidos en el art. 3.3 del Reglamento 2015/2120. La conciliación de ambas dimensiones no es fácil. Por una parte, los conceptos de discriminación, restricción e interferencia están presentes en ambos componentes, mientras que solo en el segundo se acude a los términos bloquear, ralentizar, alterar o degradar, circunstancia que puede plantear problemas de técnica jurídica a la hora de adscribir una acción a una determinada categoría y determinar si se está incumpliendo la primera, la segunda o ambas obligaciones. En realidad, la articulación del principio de neutralidad de la red en la UE plantea una problemática propia desde una perspectiva material y funcional.

\section{EL PRINCIPIO DE NEUTRALIDAD DE LA RED}

El modelo de neutralidad diseñado en el marco de la UE a partir del Reglamento 2015/2120 tiene un componente estructural y otro normativo. En cuanto al primero, el art. 5 reconoce a las ANR una serie de atribuciones y funciones en materia de supervisión y ejecución de sus disposiciones y en su apdo. 3 encomienda al ORECE la emisión de directrices para la aplicación de las obligaciones de las ANR con arreglo a dicho artículo. El segundo, el normativo, está formado por las disposiciones del reglamento y las directrices sobre neutralidad adoptadas por el ORECE con arreglo a aquella disposición. Es preciso comenzar por el marco estructural para comprender adecuadamente el apartado normativo.

\section{MARCO ESTRUCTURAL}

El sistema de gestión de la neutralidad de la red es esencialmente descentralizado. La Comisión tiene asignadas atribuciones de modo expreso en tres supuestos: a) el control de la actividad de las ANR y de los Estados en el marco de los arts. 5 y 6 mediante los informes y notificaciones que han de remitirle en relación con su actividad; b) la revisión de arts. 3, 4, 5 y 6 - a más tardar en abril de 2019- y la presentación de un informe al Parlamento y al Consejo con las propuestas necesarias, en su caso, para reformar el reglamento; y c) la estrecha cooperación con el ORECE para la adopción de las directrices. La Comisión tiene reconocida la facultad de participar, sin derecho a voto, en las deliberaciones del Consejo de Reguladores del ORECE. 
Los Estados miembros tienen atribuida la competencia para establecer las normas sobre las sanciones aplicables a las infracciones a los arts. 3, 4 y 5 y para adoptar las medidas necesarias para garantizar su aplicación, incluida la posibilidad de introducir requisitos adicionales (art. 4.3). La descentralización se explica, en particular, porque el ORECE y las ANR constituyen el marco estructural de referencia en materia de neutralidad de la red.

\subsection{EI ORECE}

La neutralidad de la red constituye un ámbito principal de acción del $\mathrm{ORECE}^{49}$, con anterioridad incluso a la adopción del Reglamento 2015/2120, que se ha traducido en una intensa actividad sobre distintos aspectos de esta materia, antes y después de la adopción de las directrices sobre aplicación de las normas europeas de neutralidad de la red por parte de las ANR $^{50}$ (BEREC, 2017a: 4). Hay que destacar tres aspectos fundamentales de su naturaleza y régimen jurídico para la comprensión del alcance y contenido de esta actividad.

En primer lugar, estructuralmente el ORECE tiene una naturaleza jurídica sui generis. El Reglamento 2018/1971 atribuye a la Oficina del ORECE -que es la Agencia de apoyo al ORECE y no al organismo como tal- la condición de órgano de la Unión, con personalidad jurídica propia, que gozará de la más amplia capacidad jurídica reconocida a las personas jurídicas por el derecho nacional de cada Estado miembro (art. 2). El ORECE está compuesto por un Consejo de Reguladores y por los grupos de trabajo (art. 6). El Consejo de Reguladores está formado por un miembro de cada Estado designado por la correspondiente $\mathrm{ANR}^{51}$.

En segundo lugar, funcionalmente el ORECE desarrolla su actividad dentro del ámbito de aplicación del Reglamento 531/2012, el Reglamento

49 El ORECE/BEREC se establece en el Reglamento (CE) 1211/2009 del Parlamento Europeo y del Consejo, de 25 de noviembre de 2009, por el que se establece el Organismo de Reguladores Europeos de las Comunicaciones Electrónicas (ORECE) y la Oficina (DO L 337, de 18 de diciembre de 2009, p. 1). El Reglamento (UE) 2018/1971, de 21 de noviembre 2018, deroga aquella norma para establecer el ORECE y la Oficina del ORECE, como Agencia de apoyo a este organismo, que sustituyen y suceden, respectivamente, al anterior ORECE y a la anterior Oficina (DO L 321, de 17 de diciembre de 2018, p. 1).

50 Véase https://bit.ly/2JZW55Z.

51 La Comisión puede participar en sus deliberaciones, pero no cuenta con derecho a voto. Es miembro de pleno derecho en el Consejo de Administración de la Oficina del ORECE (art. 15). 
2015/2120 y la Directiva 2018/1972, por la que se establece el Código Europeo de las Comunicaciones Electrónicas, para perseguir, especialmente, los propósitos enunciados en el art. 3 de esa directiva. En ese contexto se atribuye al ORECE, en particular, el objetivo de garantizar una aplicación coherente del marco regulador de las comunicaciones electrónicas. Entre sus «cometidos reguladores ${ }^{52}$, que es la denominación usada para designar un amplio abanico de actividades incluyendo labores de asistencia o asesoramiento, el art. 4.1. del Reglamento 2018/1971 incluye la adopción de dictámenes y el establecimiento de directrices, entre otros, en el marco del Reglamento 2015/2120. La amplitud de esas funciones y el valor intrínseco del objetivo de garantizar una aplicación coherente del conjunto de esas disposiciones contrasta con los cometidos asignados a la Oficina del ORECE en el art. 5 que, como es natural, se limitan a prestar asistencia al ORECE, recoger información, elaborar informes y difundir las mejores prácticas. No se entiende, tampoco desde esta perspectiva funcional, que sea la Oficina y no el ORECE quien disponga de personalidad jurídica porque sería un estatuto necesario para el propio ORECE como tal, en la medida en que resultaría coherente con el alcance y naturaleza de sus funciones y contribuiría al mejor desarrollo de las mismas.

En tercer lugar, la naturaleza y la calificación jurídica de sus actos no se ha visto reforzada con el Reglamento 2018/1971, sino que ha sufrido incluso un ligero retroceso respecto de la regulación contenida en el Reglamento1211/200953. El art. 4.4 dispone que, sin perjuicio del cumplimiento del derecho aplicable de la Unión, las ANR y la Comisión «tendrán en cuenta en la mayor medida posible las directrices, los dictámenes, las recomendaciones, las posiciones comunes, y las mejores prácticas adoptados por el ORECE para garantizar la aplicación coherente del marco regulador de las comunicaciones electrónicas». En el segundo párr. del art. 4.4 se establece una obligación de motivación por parte de las ANR cuando se aparten de la opinión del ORECE, pero limitada al caso de las directrices del art. 4.1.e), que pueden tener la particularidad de afectar a un número importante de Estados miembros o tener una dimensión transfronteriza. El alcance limitado de sus actos, desde una perspectiva jurídica, se confirma en el art. 35 del Reglamento 2018/1971, relativo a la cooperación con organismos de la

52 Esos «cometidos reguladores» son realizados por el Consejo de Reguladores del ORECE (art. 9).

53 El art. 3.3 del anterior reglamento disponía que las ANR y la Comisión «tendrán plenamente en cuenta los dictámenes, las recomendaciones, las directrices, el asesoramiento y las buenas prácticas en materia de reglamentación adoptados por el ORECE». 
Unión, terceros países y organizaciones internacionales, donde se menciona la posibilidad de concluir acuerdos de trabajo previa aprobación de la Comisión, pero aclarando que dichos acuerdos «no crearán obligaciones jurídicas» ${ }^{54}$.

En definitiva, el ORECE es un organismo y no un órgano de la UE, que no cuenta con personalidad jurídica propia, que tiene atribuido un amplio abanico de «cometidos reguladores» con el objetivo principal de garantizar una aplicación coherente del marco regulador de las comunicaciones electrónicas, para lo cual puede adoptar dictámenes y directrices que carecen de naturaleza jurídica obligatoria. Ha de desempeñar sus cometidos de manera independiente, imparcial, transparente y oportuna, pero apoyándose en la experiencia con que cuentan las ANR (art. 3.3y 4). La independencia y la objetividad son los parámetros de actuación que se asignan, también, pero por separado, en el art. 8, al Consejo de Reguladores del ORECE.

\subsection{Las ANR}

Las ANR tienen atribuida una responsabilidad principal en materia de neutralidad de la red (Carter et al., 2008: 3), que ejercen directa e individualmente $y$, de modo secundario y/o indirecto, a través del ORECE, en la medida en que designan a los miembros del Consejo de Reguladores (Marcus, 2016: 266). El art. 5.1 del Reglamento 2015/2120 atribuye a las ANR unas funciones básicas — que se entienden sin perjuicio de los cometidos que tengan asignados en sus respectivos Estados (art. 5.4) — consistentes en supervisar y velar por el cumplimiento de los arts. 3 y 4 del reglamento y promover la disponibilidad permanente de un acceso a internet no discriminatorio con niveles de calidad que reflejen los avances de la tecnología. Bajo la aparente simplicidad de estos cometidos, el régimen establecido plantea tres interrogantes de distinto alcance y naturaleza.

En primer lugar, en el ejercicio de esas funciones las ANR tienen reconocida la facultad de imponer requisitos relativos a las características técnicas, requisitos mínimos de calidad del servicio y otras medidas apropiadas y necesarias a uno o varios proveedores de comunicaciones electrónicas al público (art. 5.1) (Marcus, 2016: 269). Es una atribución que no va a estar exenta de problemas. Por una parte, amenaza la homogeneidad o uniformidad del sistema europeo en su conjunto en la medida en que permite a cada ANR crear unilateralmente obligaciones adicionales y potencialmente diferentes a las adoptadas por las otras. Por otra parte, se trata de una competencia defi-

54 En el mismo sentido puede interpretarse el régimen de responsabilidad previsto en el art. 44 del Reglamento 2018/1971. 
nida en términos muy amplios que podría entrar en colisión con lo previsto en el art. 5.5 por ir más allá de lo que el propio derecho interno reconoce como atribuciones de las ANR. Para terminar, no en orden de importancia, la adopción de este tipo de medidas puede conducir a situaciones discriminatorias entre los propios proveedores porque tengan que cumplir mayores o menores requerimientos según los casos, y puede significar que un mismo proveedor se vea obligado a cumplir requisitos distintos impuestos por las diferentes ANR en cada Estado. En este sentido, la previsión de un mecanismo de consulta previa en el marco del Consejo de Reguladores del ORECE podría haber servido para evitar diferencias, distorsiones o disfunciones derivadas de la acción unilateral que permite esta disposición.

En segundo lugar, las ANR tienen que publicar informes anuales sobre la supervisión efectuada y sus resultados y enviarlos a la Comisión y al ORECE. La elaboración de informes es generalmente una modalidad de control de la actividad de un determinado sujeto - el controlado- en el ejercicio de sus funciones - el objeto de control - por parte de otro u otros que tienen atribuida la capacidad de fiscalizar su acción. En este caso, se trata de un mecanismo de control de la actividad de las ANR aparentemente sencillo, pero realmente complejo por un doble motivo.

Por una parte, en la medida en que los destinatarios del informe son la Comisión y el ORECE, el control de la actividad de las ANR se realiza, paralelamente, a través de una institución independiente con amplias competencias en materia de cumplimiento del derecho europeo y de un organismo cuyos actos carecen de alcance jurídico vinculante y sobre cuya composición las ANR tienen el grado de influencia que supone designar a los miembros de su Consejo de Reguladores. Más allá de que este sistema, por la propia naturaleza de los órganos de control y el alcance de sus actos, propicia la aparición de valoraciones no coincidentes, constituye una fuente natural de conflicto al situar a la Comisión — defensora del interés comunitario- y al ORECE, como órganos de control, dentro de un modelo de gestión de la neutralidad marcadamente intergubernamental en que las ANR asumen la posición individual de controlado y, por intermediación en su composición, la colectiva de controlador.

Por otra parte, la complejidad de este modelo de control deriva del hecho de que se trata de fiscalizar la actividad de las ANR en relación con la supervisión del cumplimiento de las medidas previstas en los arts. 3 y 4 del Reglamento 2015/2120. El problema estriba en que esas normas son obligatorias y hay vías de recurso en caso de incumplimiento. Pero las directrices de desarrollo de esas normas adoptadas por el ORECE, como el resto de los actos de este organismo, no tienen carácter vinculante y ni siquiera resulta obligatorio motivar en todos los supuestos las razones por las que no 
se les ha dado cumplimiento. Si se controla estrictamente solo el cumplimiento de las normas del reglamento, se estaría limitando el efecto útil de las directrices. Si se controla el respeto de las disposiciones del reglamento siguiendo la interpretación realizada en las directrices sobre neutralidad, se está otorgando un valor jurídico a las mismas que no se corresponde con la naturaleza que les reconoce el art. 4.4 del Reglamento 2018/1971. Este problema puede materializarse fácilmente si esa interpretación restrictiva o extensiva perjudica a terceros puesto que en ambos casos contarían con argumentos para su impugnación.

En tercer lugar, las ANR ejercen una función de control sobre los proveedores de servicios de comunicaciones electrónicas en relación con el cumplimiento de las obligaciones establecidas en los arts. 3 y 4 del Reglamento 2015/2120. La cuestión es si esa función podría entrar en colisión con las atribuciones de la Comisión en materia de control del respeto del derecho comunitario si esta institución entiende que ha de intervenir frente a un proveedor que está incurriendo en un incumplimiento, si ha de esperar hasta que actúe la ANR o si ha de hacerlo frente a la propia ANR por no cumplir con sus funciones de control respecto de dicho proveedor.

El modelo orgánico y funcional compuesto por las ANR y el ORECE tiene asignadas, en virtud del art. 5, las medidas de supervisión y ejecución en relación con el cumplimiento de las disposiciones contenidas en los arts. 3 y 4 del reglamento. El art. 5.3 encomienda al ORECE emitir directrices para la aplicación de las obligaciones de las ANR «con arreglo al presente artículo». Esa previsión se ha traducido en la adopción de unas directrices que interpretan el conjunto del reglamento bajo la denominación de directrices sobre neutralidad. La relación entre ese concepto y el de Internet abierta es un componente esencial dentro de ese marco normativo.

\section{MARCO NORMATIVO}

El análisis de la evolución del concepto de neutralidad y de la normativa contenida en el Reglamento 2015/2120 (Marcus, 2016: 273) y en las directrices del ORECE obliga a plantearse la distinción y la relación entre los conceptos de internet abierta y neutralidad. El primero se usa en el reglamento y el segundo en las directrices. Ninguno es objeto de definición en estas disposiciones, pero la interpretación de las mismas permite llegar a algunas conclusiones.

En primer lugar, el Reglamento 2015/2120 incluye en su art. 3, bajo la denominación "Salvaguardia del acceso a internet abierta», contenidos normalmente 
atribuidos al principio de neutralidad, pero sin utilizar esa expresión ${ }^{55}$. En esa disposición se reconoce a los usuarios finales un conjunto de derechos que, junto con las medidas de transparencia del art. 4 y de información del art. 5, se identifican como manifestaciones del concepto de Internet abierta.

En segundo lugar, siguiendo lo dispuesto en su primer apartado, las directrices sobre neutralidad del ORECE «are designed to provide guidance on the implementation of the obligations of NRAs. Specifically, this includes the obligations to closely monitor and ensure compliance with the rules to safeguard equal and non-discriminatory treatment of traffic in the provision of internet access services and related end-users rights as laid down in Articles 3 and $4{ }^{56}$. La especificación de ese objetivo y la denominación misma del acto permiten adscribir el concepto de neutralidad a las obligaciones asignadas a los proveedores de comunicaciones electrónicas.

En consecuencia, siguiendo las disposiciones del reglamento y de las directrices, cabe interpretar que el concepto de internet abierta comprende los derechos de los usuarios finales, mientras que la neutralidad de la red se sitúa en el contexto de las obligaciones de los proveedores de servicios. En principio, operarían como distintas caras de una misma moneda: los derechos de los usuarios en el marco de una internet abierta frente a las obligaciones de los proveedores derivadas del principio de neutralidad de la red. La neutralidad, definida en términos negativos como un conjunto de prohibiciones, constituiría no solo el medio sino, también, el complemento necesario para alcanzar el objetivo de la internet abierta ${ }^{57}$, definida en sentido positivo como un conjunto de derechos de acceso y tráfico, no discriminación y transparencia, porque también esas medidas, como indica el propio título del art. 4, están destinadas a garantizar el acceso a la Internet abierta (Alú, 2017: 93).

El concepto de internet abierta abarca los aspectos relativos al estatuto de los usuarios finales, los derechos de acceso y tráfico, el derecho a un trato equitativo y no discriminatorio y las condiciones de ejercicio de esos derechos, que vienen determinadas en el párr. 2 del art. 3.1, en el art. 3.2 y en el párr. 2 del art. 3.3 del reglamento y desarrollados en las directrices sobre neutralidad.

55 La única mención se realiza en el considerando 2, donde se reconoce el principio de neutralidad tecnológica, es decir, como el propio texto aclara, que las medidas previstas en esta norma «no imponen el uso de ningún tipo particular de tecnología ni discriminan a su favor».

56 Véase https://berec.europa.eu/eng/netneutrality/.

57 "There is also reason to believe tan open access alone can be an insufficient remedy for many of the likely instances of network discrimination» (Wu, 2005: 142). 
El concepto de neutralidad de la red se circunscribe a las dos obligaciones de los proveedores de comunicaciones electrónicas siguiendo lo previsto en el art. 3.3 del reglamento :a) tratar todo el tráfico de manera equitativa, sin discriminación, restricción o interferencia, con independencia del emisor y el receptor, el contenido, las aplicaciones o servicios o el equipo terminal empleado; y b) no bloquear, ralentizar, alterar, restringir, interferir, degradar ni discriminar entre contenidos, aplicaciones o servicios concretos o categorías específicas, excepto en caso necesario y únicamente durante el tiempo necesario en los supuestos contemplados en el art. 3.3. (BEREC, 2016: 13-20).

La primera obligación de los PSI es una manifestación del principio básico, asentado en el derecho y en la jurisprudencia europea, de que no debe darse un trato diferente a situaciones comparables, ni un trato similar a situaciones diferentes, a menos que tal trato este objetivamente justificado, situándolo en el contexto de la actividad cibernética ${ }^{58}$. La segunda obligación se concreta en una enumeración no exhaustiva de prácticas constitutivas de una discriminación o un trato no equitativo y de prácticas que podrían estar prohibidas por su mera producción sin necesidad de que se traduzca objetivamente en una discriminación. Bloquear, ralentizar, alterar, restringir, interferir o degradar el tráfico son acciones prohibidas por sí mismas sin necesidad de probar la existencia de una discriminación. Ello confirma que la neutralidad no es simplemente la traducción al marco de la red del principio de no discriminación, sino que implica esa otra obligación adicional de los PSI que distingue la neutralidad del principio de no discriminación, contribuyendo a su calificación como categoría autónoma. Es algo más y diferente porque supone la prohibición de determinadas prácticas, aunque no sean discriminatorias. Pero también es algo menos o algo más limitado porque el reglamento establece excepciones y limitaciones en los apdos. 3 y 5 del art. 3.

La previsión de estas limitaciones y excepciones del art. 3 tiene, en realidad, un doble efecto. Por una parte, no permite definir el contenido del reglamento solo en términos de internet abierta, porque esas disposiciones estarían contrariando esa idea, lo que implica la necesidad de invocar el concepto de neutralidad para abarcar aquellos aspectos que no tendrían cobertura bajo el concepto de Internet abierta. Por otra parte, obliga a adscribir las limitaciones y excepciones a cada uno de los dos componentes de la

58 La defensa de la neutralidad como prohibición de discriminación cuenta con detractores que defienden los beneficios de discriminar el acceso y el tráfico y la necesidad de construir a balanced policy (Peha et al., 2007: 664-665; Wu, 2005: 151; Shelansky, 2007: 35) o de garantizar la flexibilidad del mercado (Morales y Pérez, 2015: 251). 
neutralidad porque solo mediante esa operación puede determinarse su alcance y contenido jurídicos.

El Reglamento 2015/2120 establece limitaciones y excepciones a la neutralidad de la red que, en algún caso, suponen atribuciones para los PSI y, en cualquiera de los supuestos, se reconocen y forman parte de la definición y de la aplicación del concepto de neutralidad permitiendo su diferenciación respecto del principio de no discriminación. Estos aspectos, que modulan el alcance y contenido de la neutralidad, se encuentran definidos en el art. 3.3 y en el art. 3.5 del reglamento y traen causa, en mayor o menor medida, de los requerimientos técnicos que impone el funcionamiento de la red. El reglamento no solo implica un cambio en los contenidos materiales de la neutralidad, al privilegiar el concepto de internet abierta, sino una reducción adicional de los mismos porque incorpora limitaciones y excepciones que restringen el alcance de la neutralidad. Para algún sector de la doctrina, esta norma dinamita el principio de neutralidad al permitir la existencia de servicios especiales de pago y establecer excepciones discriminatorias para la gestión del tráfico (González San Juan, 2016: 43).

\section{ALCANCE Y LÍMITES DE LA NEUTRALIDAD DE LA RED}

El art. 3 del Reglamento 2015/2120 incluye tres supuestos que son identificados como limitaciones al principio de neutralidad de la red, a saber: las medidas de gestión razonable del tráfico, las excepciones contempladas en el último párr. del art. 3.3 y los servicios especializados del art. 3.5. Los tres supuestos pueden estar, en mayor o menor medida, justificados por razones de orden técnico o jurídico o resultar, en mayor o menor sentido, discutibles (Carter et al., 2008: 18). Un problema añadido es que la interpretación realizada al respecto en las directrices sobre neutralidad parece ir más allá de lo previsto en el reglamento.

\subsection{Medidas de gestión del tráfico}

El Reglamento 2015/2120 reconoce, en el párr. segundo del art. 3.3, que la obligación de tratar el tráfico de manera equitativa y no discriminatoria no impide a los PSI aplicar medidas razonables de gestión del tráfico. La justificación técnica de tales medidas y la determinación de su «razonabilidad» se explican en el reglamento y en las directrices sobre neutralidad sobre la base de cuatro criterios: 1) han de ser transparentes, no discriminatorias y proporcionadas (Carter et al., 2008: 6-10); 2) han de estar basadas en requisitos objetivos de calidad técnica para categorías específicas de tráfico y no en motivaciones comerciales (Schewick, 2015: 
124; BEREC, 2016: 17-18); 3) no supervisarán el contenido específico de los datos que se transmiten y no se mantendrán por más tiempo del necesario (Marsden, 2012: 28; BEREC, 2018: 10); y 4) respetarán la normativa europea sobre protección de datos y privacidad de las comunicaciones electrónicas (BEREC, 2016: 24). El desarrollo de esta obligación en las directrices es, sin embargo, problemático ${ }^{59}$.

\subsection{Excepciones}

Las excepciones solo pueden ser adoptadas, en caso necesario y únicamente durante el tiempo necesario (Carter et al., 2008: 23), en los tres supuestos contemplados en el párr. tercero del art. 3.3, que constituyen un

59 De acuerdo con las directrices, las ANR deben comprobar si el tratamiento de datos personales en ese contexto por parte de un PSI es necesario y proporcionado. Mientras, las autoridades nacionales competentes en materia de protección de datos habrán de comprobar su conformidad con el derecho europeo en la materia (BEREC, 2016: 24). Este sistema de control del cumplimiento de la normativa plantea dos problemas. En primer lugar, en las directrices no se hace referencia a la privacidad, que es distinta de la protección de datos personales y que es mencionada expresamente en el art. 3.4 del reglamento. No se entiende esa ausencia de mención, en particular tratándose de las comunicaciones electrónicas. En segundo lugar, la distribución de funciones entre las ANR y las autoridades nacionales competentes en materia de protección de datos realizada en los apdos. 97 y 98 de las directrices no va a estar exenta de problemas, básicamente por dos motivos: por tratarse de materias en las que concurren las atribuciones de ambos tipos de organismos y es necesario precisar el alcance de sus respectivas atribuciones y porque la articulación de los mismos en cada uno de los Estados miembros puede ser diferente y dificultar el funcionamiento práctico de este sistema. En la medida en las ANR designan a los miembros del Consejo de Reguladores del ORECE, se puede explicar que se hayan reconocido la competencia para determinar el cumplimiento de los requisitos de necesidad y proporcionalidad por parte de los PSI en el tratamiento de datos de conformidad con los objetivos del art. 3.3. Pero, por otra parte, se adivina complicado que las autoridades nacionales de protección de datos acepten verse excluidas del análisis de esos requisitos respecto de la actividad de tratamiento de datos de los PSI, al que se encuentran obligadas conforme a la normativa europea sobre protección de datos. Habría sido necesario establecer un mecanismo de coordinación entre ambos organismos en la línea, por ejemplo, del diseñado para los incidentes que afectan a datos en el marco de la Directiva 2016/1148 en materia de seguridad de redes y sistemas de información. La interpretación realizada en las directrices va más allá de lo previsto en el reglamento al asignar esa función a las ANR, además de obviar la privacidad que es precisamente un derecho nuclear en el marco de las comunicaciones electrónicas. 
listado exhaustivo, y han de ser objeto de una interpretación estricta sujeta al requisito de proporcionalidad.

a) Cumplimiento de obligaciones jurídicas.

La primera excepción se justifica por la necesidad de «cumplir los actos legislativos de la Unión o la legislación nacional acorde con la de la Unión, a la que el proveedor de servicio de acceso a internet esté sujeto, o las medidas que cumplan dicho Derecho de la Unión para hacer efectivos actos legislativos de la Unión o de la legislación nacional, incluidas las sentencias de tribunales o autoridades públicas investidas con los poderes pertinentes» [art. 3.3, párrafo tercero, a)] (BEREC, 2012b: 27). Esta disposición merece críticas formales y de fondo. La redacción debería ser más precisa y su formulación más comprensible. El considerando 13, que explica esta previsión del reglamento, tampoco merece una valoración positiva.

Como primera providencia, esta normativa hace referencia a actos «legislativos» de la Unión mientras que el considerando 13 se refiere a «la obligación de cumplir el Derecho de la Unión se refiere, entre otras cosas, al cumplimiento de las disposiciones de la Carta de los Derechos Fundamentales de la UE». El art. 3.3 y el mismo considerando podrían haberse referido al cumplimiento del derecho de la UE en su conjunto y sin obviar ninguna de sus fuentes de creación normativa incalificables como «legislativas». En segundo término menciona «la legislación nacional acorde con la de la Unión». No se explica esa limitación cuando podría existir normativa nacional, en particular si no es acorde con el derecho de la Unión, que justifique la adopción de estas excepciones derivadas de la necesidad de cumplimiento de obligaciones jurídicas. En tercer lugar, la referencia a «sentencias de tribunales o autoridades públicas investidas con los poderes pertinentes» es criticable tanto por mezclar actos de tan diferente naturaleza como por la imprecisión de utilizar la expresión "sentencia» para referirse a actos de «autoridades públicas investidas con los poderes pertinentes», que es, por otra parte, también una definición bastante imprecisa. Para terminar, tampoco se entiende el recurso a la Directiva 2002/21/CE para justificar que «únicamente pueden adoptarse medidas susceptibles de restringir los derechos y libertades fundamentales si son apropiadas, proporcionadas y necesarias en una sociedad democrática». Aunque se encuentre previsto en esa directiva, su alcance y naturaleza exceden con mucho lo que esa remisión pueda significar. No solo se trata de un principio recogido en el Convenio Europeo para la Protección de los Derechos Humanos y de las Libertades Fundamentales (CEDH), como indica el considerando 13, sino que forma parte de la Carta de Derechos Fundamentales de la Unión Europea (CDFUE) y de la jurisprudencia consolidada del TJUE. En 
las directrices del ORECE se menciona expresamente a esos efectos el art. 52 de la Carta.

b) Integridad y seguridad de redes y servicios.

Esta excepción está destinada a "preservar la integridad y la seguridad de la red, los servicios prestados a través de ella y los equipos terminales de los usuarios finales». Las directrices sobre neutralidad identifican amenazas y ataques a la seguridad y/o integridad, para concluir que las medidas a adoptar en este supuesto consistirían básicamente en restringir las conexiones o bloquear el tráfico desde o hacia determinados puntos específicos (BEREC, 2016: 21-22).

El uso de sistemas de monitorización del tráfico por razones de seguridad por parte de los PSI no solo está justificado, sino que debería implementarse de modo continuado. Por ese motivo, en este caso no resultaría de aplicación el requisito de mantenimiento de las medidas exclusivamente el tiempo necesario. Pero, como se trata de una excepción que, por su contenido y su finalidad, podría propiciar prácticas contrarias al reglamento, las ANR deben evaluar cuidadosamente el cumplimiento de los requisitos para acogerse a esta excepción y solicitar a los PSI las justificaciones necesarias al efecto. En este aspecto, la principal crítica apunta al hecho de que habría sido necesario coordinar esas medidas con la normativa europea en materia de seguridad de redes y sistemas de información, incluyendo modalidades de cooperación entre las ANR y los organismos y agencias con competencias operativas en esa materia. La coordinación en este punto es absolutamente indispensable.

c) Congestión de la red.

Esta excepción está permitida para «evitar la inminente congestión de la red y mitigar los efectos de congestiones de la red excepcionales o temporales», siempre que categorías equivalentes de tráfico se traten de manera equitativa y de acuerdo con el principio de proporcionalidad.

El reglamento recoge dos modalidades: la congestión temporal y la congestión excepcional. Las directrices del ORECE distinguen entre una congestión inminente, que puede prevenirse, y una congestión excepcional cuyos efectos pueden mitigarse (Greenstein et al., 2016: 20; BEREC, 2012b: 29). Las calificaciones "temporal» del reglamento e «inminente» de las directrices no son equiparables y admiten un margen de apreciación que no va a estar exento de problemas. Una congestión temporal no es igual a una congestión inminente como causas que permiten acogerse a esta excepción. Ello implica que la primera estará justificada por el reglamento 
y la segunda por las directrices. No se explica el porqué de esa falta de coherencia.

\subsection{Servicios especializados}

El art. 3.5 del Reglamento 2015/2120 formaliza jurídicamente la prestación de los denominados «servicios especializados» como una facultad reconocida a todos los proveedores de comunicaciones electrónicas al público, incluidos los PSI y los PAC (Morales y Pérez, 2015: 118). Las directrices explican que se trata de la prestación de servicios distintos del acceso a internet y optimizados para determinados contenidos, aplicaciones o servicios porque esa optimización es objetivamente necesaria por razones de calidad del servicio (Belli y Bergen, 2013: 30; BEREC, 2012a: 48; BEREC, 2018: 11). Los servicios especializados constituyen una excepción a las dos categorías de obligaciones incluidas en el principio de neutralidad que está sujeta a unos requisitos (Marcus, 2016: 276) cuyo control se atribuye a las ANR ${ }^{60}$.

El problema de fondo que plantea esta categoría es que su existencia misma se identifica como una vulneración de la neutralidad de la red o una limitación significativa de su alcance y contenido. Las garantías que ofrece el conjunto de condiciones que impone el reglamento podrían ser suficientes para limitar el impacto de este tipo de servicios sobre la neutralidad. No obstante, las amplias funciones reconocidas a las ANR en las directrices, que van mucho más allá de lo expresado en el considerando 16 del reglamento, aumentan las posibilidades de una interpretación no uniforme de este tipo de servicios, cuestionables por sí mismos desde la perspectiva de la neutralidad.

60 Estos servicios están sujetos a tres condiciones: a) solo podrán prestarse si la capacidad de la red es suficiente para ofrecerlos aparte y además de los servicios de acceso a internet en funcionamiento, circunstancia que será evaluada por la ANR; b) no serán utilizables ni ofertados como sustitución de los servicios de acceso a internet; c) no podrán ir en detrimento de la disponibilidad o de la calidad general de los servicios de acceso a Internet para los usuarios finales (BEREC, 2017b: 4). Con carácter general, las ANR pueden evaluar si la prestación de servicios especializados reduce la calidad general de los servicios de acceso a internet y deben intervenir si se detectan disminuciones persistentes del rendimiento de esos servicios de acceso. Las ANR deben verificar si la optimización ofrecida por los servicios especializados es objetivamente necesaria y en qué medida lo es para ofrecer un aseguramiento de calidad al usuario final. El propósito es evitar que se trate de la concesión de una prioridad general con respecto a contenidos, aplicaciones y servicios comparables disponibles a través del servicio de acceso a internet y una forma de eludir las disposiciones del reglamento. 


\section{CONCLUSIONES}

La neutralidad de la red es objeto de una polémica constante. La evolución tecnológica supone operar sobre una realidad compleja y cambiante en la que es necesario conjugar los derechos y obligaciones y la variedad de intereses y prioridades de usuarios, PSI y PAC. Si la idea de neutralidad encuentra detractores, aún siguen siendo mayores en número y en autoridad quienes defienden este principio. Más allá de la necesidad de ajustar su alcance y contenido, como consecuencia del propio cambio tecnológico y de los correspondientes ajustes de intereses, la mayoría de Estados, organizaciones y foros internacionales desarrollan o apoyan el principio de neutralidad como un componente esencial dentro del funcionamiento de las redes y del ciberespacio. Las reacciones que ha provocado la adopción de la Restoring Internet Freedom Order en EE. UU., como prueba el enfrentamiento entre la Cámara de Representantes y el Senado, evidencian la necesidad, el valor y la importancia del principio de neutralidad de la red (Glass y Tardiff, 2019: 199).

El modelo de neutralidad de la red diseñado en el marco de la UE adolece de dos problemas principales, conceptuales y funcionales, de orden general: el no reconocimiento del carácter y la naturaleza transversal de la neutralidad y la indeterminación de su alcance y su contenido. El primero se produce por la adscripción de la neutralidad de la red al marco regulador de las comunicaciones electrónicas, soslayando que es una categoría que opera en un contexto normativo, material, funcional y teleológico considerablemente más amplio. No solo se aplica en otros ámbitos que van desde el comercio electrónico a la sociedad de la información, pasando por los derechos de los consumidores o las reglas de competencia, sino que, además, constituye un medio y una garantía de respeto y protección de derechos y libertades básicos como la información, la expresión, la privacidad, la confidencialidad de las comunicaciones, la protección de datos personales y la no discriminación. La neutralidad no se limita al sector de las comunicaciones electrónicas, como ocurría en el siglo xIx. Situada ahora en el marco de la sociedad y de la economía del conocimiento, como demuestra la práctica existente a nivel internacional y en el ámbito interno, es un principio que opera respecto de una pluralidad de ámbitos materiales de actuación y se manifiesta como un instrumento para el ejercicio y la garantía de aquellos derechos básicos. La naturaleza transversal de la neutralidad de la red es incuestionable y determinante en su articulación jurídica. Un tema distinto es que no se haya alcanzado el consenso necesario en el marco de la UE para asumir esa situación por las divergencias de criterio entre sus Estados y sus instituciones. En ese caso, urge buscar soluciones en la línea de una progresiva aproximación y conciliación de las respectivas posiciones. En caso contrario, si esta regulación no es obra del 
disenso, urge además poner de manifiesto la existencia misma del problema que plantea la adopción de esa visión formalista y sectorial de la neutralidad de la red.

El segundo de los problemas - la indeterminación del alcance y del contenido de la neutralidad de la red- es, en gran medida, consecuencia del no reconocimiento de su naturaleza transversal. Pero se manifiesta como un problema diferenciado desde el momento en que se acude para su solución al principio de trato equitativo y no discriminatorio. Esta operación implica despojar a la neutralidad de la red de su componente axiológico — desplazándolo, además, al concepto jurídicamente indeterminado de internet abiertay cuestionar su naturaleza como categoría jurídica autónoma porque se define como objetivo político. La relación entre los conceptos de Internet abierta y neutralidad de la red no está exenta de controversia. El primero, jurídicamente indeterminado, está formalizado jurídicamente en el Reglamento 2015/2120. El segundo, careciendo de esa formalización jurídica, está definido en sus contenidos esenciales en dicho reglamento y desarrollado en las directrices del ORECE. La idea de internet abierta no tiene en la práctica internacional $y$ en las normativas internas la naturaleza como categoría jurídica que, sin embargo, se reconoce a la neutralidad de la red en el derecho interno de un número cada vez mayor de países (Morales y Pérez, 2015: 130-226; Belli y De Filippi, 2016: 4).

Además de esos problemas de carácter general, la interpretación del Reglamento 2015/2120 y de las directrices sobre neutralidad del ORECE permiten identificar algunos problemas específicos respecto de los cuales es preciso arbitrar soluciones.

El modelo de neutralidad de la red en la UE necesita, en primer lugar, una definición del concepto de neutralidad y de la idea de internet abierta que permita identificar, diferenciar y gestionar ambas categorías. Es cierto que la práctica internacional y la normativa interna no son uniformes, ni siquiera cercanamente coincidentes, pero también es verdad que la neutralidad de la red ha sido formalizada jurídicamente en numerosos ordenamientos jurídicos internos hasta el punto de ser considerada una libertad, un derecho y un principio, mientras que la apertura de internet no cuenta con ese sustrato normativo y se sitúa en mayor medida en el terreno de los valores que en el de las reglas jurídicas. Esa operación puede limitarse a asociar la neutralidad de la red al principio de trato equitativo y no discriminatorio, en cuyo caso habrá que motivar esa decisión, que implica despojarla de su contenido axiológico y privarla de la condición de categoría jurídica autónoma, y justificar su necesidad dado que ya existe ese otro principio. Pero esa operación puede servir, por el contrario, para afirmar la neutralidad de la red como un principio básico en el entorno creado con la aparición del ciberespacio que comprende 
los derechos de acceso y tráfico, transparencia, tratamiento equitativo y no discriminación entre usuarios finales, PSI y PAC, salvo por excepciones razonables y justificadas. Esto es, en definitiva, la neutralidad entendida como la expresión jurídica del valor de una Internet abierta y su instrumento de garantía.

El modelo de neutralidad de la red en el marco de la UE requiere, en segundo lugar, el reconocimiento del alcance y la naturaleza transversal de este principio. Ello implica actuar en una doble dirección: por una parte, entender la necesidad de estudiar su aplicación, más allá del sector regulador de las comunicaciones electrónicas, en el marco de los ámbitos materiales susceptibles de verse afectados por el mismo, en particular, competencia, consumidores, comercio electrónico, economía digital y sociedad de la información; y, por otra parte, asumir la obligación de analizar este principio en el contexto de los derechos y libertades básicos reconocidos en la CDFUE y en el CEDH, en particular, información, expresión, privacidad, confidencialidad de las comunicaciones, protección de datos personales y no discriminación.

El modelo de neutralidad de la red requiere, en tercer lugar, algunos cambios en su modelo de gestión. Por una parte, habría que plantearse la necesidad de mejorar el estatuto jurídico del ORECE asignándole personalidad jurídica y garantizando una mayor efectividad a sus decisiones. Por otra parte, habría que reformular la posición y atribuciones de las ANR desde varias perspectivas: a) limitar la facultad que tienen asignada en el art. $5.1 \mathrm{del}$ Reglamento para imponer requisitos adicionales sobre características técnicas o de otra naturaleza con objeto de contribuir a la uniformidad y homogeneidad del sistema evitando que cada ANR singularice un modelo propio y potencialmente diferente del resto; b) mejorar el diseño del modelo de control de la actividad de las ANR, así como respecto de los PSI y los PAC, garantizando el ejercicio de una supervisión independiente y externa; c) adaptar las atribuciones de las ANR en el marco del ORECE para favorecer una mejora del estatuto jurídico de este organismo; y d) articular mecanismos de coordinación de la actividad de las ANR respecto de las autoridades nacionales competentes en materia de protección de datos y de seguridad de redes y sistemas de información en los supuestos en los que, por tratarse de esos ámbitos, puedan producirse interferencias en las atribuciones respectivas. Para terminar, en el plano normativo se requeriría mejorar la redacción de la excepción relativa al cumplimiento de obligaciones jurídicas, determinar con mayor precisión la relación entre las medidas razonables de tráfico y la excepción basada en la congestión de la red y plantear la necesidad y oportunidad de la categoría de los servicios especializados.

El debate sobre la neutralidad de la red sigue y seguirá abierto porque forma parte de la genética y de la evolución del ciberespacio y de las TIC. La 
articulación de un modelo dentro de la UE — que reconozca su naturaleza transversal, que identifique claramente su contenido y que resulte funcional y operativo- no solo es necesaria en el contexto de ese debate, sino que se convierte en un imperativo por el alcance y el contenido mismo de este principio dentro de una sociedad y una economía del conocimiento.

\section{Bibliografía}

Alú, A. (2017). Il diritto de acceso ad Internet nell'ordinamento europeo. En M. R. Allegri y G. D'Ippoliti (coords.). Accesso a internet e neutralità della rete fra principi costituzionali e regole europee (pp. 93-107). Roma: Aracne Editrice.

ACLU (2013). Why The Government Must Act To Preserve The Free And Open Internet. Disponible en: https://bit.ly/2Xhm8IJ.

Barata Mir, J. (2012). El concepto de Net Neutrality y la tensión entre regulación y pública y autorregulación privada de las redes. Revista de Internet, Derecho y Politica, 13, 44-52. Disponible en: https://doi.org/10.7238/idp.v0i13.1480.

Bauer, J. M. (2007). Dynamic Effects of Network Neutrality. International Journal of Communication, 1, 531-547. Disponible en: https://bit.ly/2wrb5AQ.

Beard, R., Ford, G. S, Koutsky, T. M. y Spiwak, L. J. (2007). Network Neutrality and Industry Structure. Hastings Communications and Entertainment Law Journal, 29, 149-169. Disponible en: https://bit.ly/2XhmSgZ.

Belli, L. y Bergen, M. van (2013). Protecting Human Rights through Network Neutrality: Modernising Human Rights and Safeguarding the Open Internet. Steering Committee on Media and Information Society (CDMSI). Disponible en: https://bit.ly/2EF01Vl.

Belli, L. y De Filippi, P. (eds.) (2016). Net Neutrality Compendium: Human Rights, Free Competition and the Future of the Internet. Heidelberg: Springer. Disponible en: https://doi.org/10.1007/978-3-319-26425-7.

BEREC (2011). Guidelines on Transparency in the scope of Net Neutrality: Best practices and recommended approaches. BoR (11) 67. Riga: BEREC Office.

- (2012a). Guidelines for quality of service in the scope of net neutrality. BoR (12) 131. Riga: BEREC Office.

(2012b). Differentiation practices and related competition issues in the scope of net neutrality. BoR (12) 132. Riga: BEREC Office.

(2015). How Do Consumers Value Net Neutrality In An Evolving Internet Marketplace? A report into ecosystem dynamics and demand-side forces Guidelines on Transparency in the scope of Net Neutrality: Best practices and recommended approaches. BoR (15) 65. Riga: BEREC Office.

- (2016). Guidelines on the Implementation by National Regulators of European Net Neutrality Rules. BoR (16) 127. Riga: BEREC Office.

— (2017a). Strategy 2018-2020. BoR (17) 109. Riga: BEREC Office. 
— (2017b). Net Neutrality Regulatory Assessment Methodology. BoR (17) 178. Riga: BEREC Office.

- (2018). Opinion for the evaluation of the application of Regulation (EU) 2015/2120 and the BEREC Net Neutrality Guidelines. BoR (18) 244. Riga: BEREC Office.

Berners-Lee, T. (2010). Long Live the Web: A Call for Continued Open Standards and Neutrality. Scientific American. Disponible en: https://bit.ly/2WHhnLD.

Carter, K. R., Marcus, J. S. y Wernick, C. (2008). Network Neutrality: Implications for Europe. WIK Diskussionsbeitrag, 314.

Cheng, A. S. (2012). Values of Stakeholders in the Net Neutrality Debate: Applying Content Analysis to Telecommunications Policy. Disponible en: https://bit. ly/2JPy9So.

Cheruvalath, R. (2018). Internet Neutrality. A Battle Between Law and Ethics. International Journal Semiot Law, 31, 145-153. Disponible en: https://doi. org/10.1007/s11196-017-9531-z.

Cullell March, C. (2011). La neutralidad de la red y las libertades en la reforma de las comunicaciones electrónicas de la Unión Europea: ¿Están presentes en toda Europa? En A. Cerrillo i Martínez, M. Peguera, I. Peña-López y M. Vilasau Solana (coords). Neutralidad de la red y otros retos para el futuro de Internet: Actas del VII Congreso Internacional, Internet, Derecho y Politica (pp. 67-77). Barcelona: UOC; Huygens.

Frieden, R. (2008). Internet Packet Sniffing and Its Impact on the Network Neutrality Debate and the Balance of Power Between Intellectual Property Creators and Consumers. Fordham Intellectual Property, Media and Entertainment Law Journal, 18 (3), 633-675. Disponible en: https://bit.ly/2XnCXlq.

(2015). What's New in the Network Neutrality Debate. Michigan State Law Review, 739-786. Disponible en: https://doi.org/10.2139/ssrn.2502122.

Friedlander, S. A. (2016). Net Neutrality and the FCC's 2015 Open Internet Order. Berkeley Technology Law Journal, 31, 905-929.

Gilroy, A. A. (2018). The Net Neutrality Debate: Access to Broadband Networks. Congressional Research Service. Disponible en: https://bit.ly/2G7VREn.

Glass, V. y Tardiff, A. (2019). A new direction for the net neutrality debate. Telecommunications Policy, 43, 199-212. Disponible en: https://doi.org/10.1016/j. telpol.2018.05.002.

González San Juan, J. L. (2016). Neutralidad de red en Internet. Ibersid, 10 (2), 39-44.

Greenstein, S., Peitz, M. y Valleti, T. (2016). Net Neutrality: A Fast Lane to Understanding the Trade-Offs. NBER Working Paper, 21950. Disponible en: https:// doi.org/10.3386/w21950.

Ly, A., MacDonald, B. H y Toze, S. (2012). Understanding the Net Neutrality: Listening to Stakeholders. Peer Review Journal on the Internet, 17 (5). Disponible en: https://doi.org/10.5210/fm.v17i5.3857. 
Ma, R. T. B. y Misra, V. (2013). The public option: a nonregulatory alternative to network neutrality. IEEE/ACM Trans. Netw. 21 (6), 1866-1879. Disponible en: https://doi.org/10.1109/TNET.2012.2237412.

Manner, J. A. y Hernández, A. (2014). An Overlooked Basis of Jurisdiction For Net Neutrality: The World Trade Organization Agreement on Basic Telecommunications Services. CommLaw Conspectus, 22, 61-82.

Marcus, J. S. (2016). New Network Neutrality Rules in Europe: Comparisons to Those in the U.S. Colorado Technology Law Journal, 14, 259-280. Disponible en: https://bit.ly/2MuPwKK.

Marsden, C. T. (2012). Neutralidad de la Red: Historia, regulación y futuro. Revista de Internet, Derecho y Politica, 13, 24-43. Disponible en: https://doi.org/10.7238/ idp.v0i13.1394.

Marsocci, P. (2017). La rete Internet come spazio di partecipazione democratica. En M. R. Allegri y G. D'Ippoliti (coords.). Accesso a internet e neutralità della rete fra principi costituzionali e regole europee (pp. 45-54). Roma: Aracne Editrice.

Morales Espinosa, P. F. y Pérez González, M. E. (2015). La neutralidad de la red y los fundamentos de su aplicación como principio general en el derecho. [Tesis universitaria] Universidad de Chile.

OCDE (2011). Council Recommendation on Principles for Internet Policy Making. Disponible en: https://bit.ly/2KgofZB.

(2015). Economic and Social Benefits of Internet Openness. Disponible en: https:// bit.ly/2Xfew9n.

Orozco Salgado, M. J. (2015). El principio de neutralidad de la red. Revista de Derecho, 18, 91-122. Disponible en: https://doi.org/10.5377/derecho.v0i18.1993.

Parlamento Europeo (2014). Network Neutrality Revisited: Challenges and Responses in the EU and the US. Luxemburgo: Dirección General de Políticas Internas.

Peha, J. M. (2006). The Benefits and Risks of Mandating Network Neutrality, and the Quest for a Balanced Policy. 34th Telecommunications Policy Research Conference. Disponible en: https://bit.ly/2QzlmnP.

Peha, J. M., Lehr, W. H. y Wilkie, S. (2007). The State of the Debate on Network Neutrality. Carnegie Mellon University. Department of Engineering and Public Policy.Paper 29. Disponible en: https://bit.ly/2HMxbEj.

Pisanty, A. y Huesca, E. (2015). Neutralidad de la red en Internet. México D. F.: Universidad de México.

Rodríguez Miranda, C. y Carboni, O. (2015). La genealogía del principio de la neutralidad de la red. En XVII Congreso de la Red de Carreras de Comunicación Social y Periodismo de Argentina (Córdoba, 25-26 de agosto de 2015): La institucionalización de los debates, estudios e incidencia social del campo de la comunicación. Córdoba: Argentina.

Schewick, B. van (2005). Towards an Economic Framework for Network Neutrality Regulation. TPRC 2005. The 33rd Research Conference on Communication, Information and Internet Policy. Disponible en: https://bit.ly/2zHukqq. 
(2015). Network Neutrality and Quality of Service: What a Non-Discrimination Rule Should Look Like. Standford Law Review, 67, 1. Disponible en: https://bit.ly/2EMMcEh.

Shelansky, H. A. (2007). Network Neutrality: Regulating with More Questions tan Answers. Journal of Telecommunications and High Technology Law. 6, 23-40. Disponible en: https://bit.ly/2Xh2z33.

Sidak, J. G. (2006). A Consumer-Welfare Approach to Network Neutrality Regulation of the Internet. Journal of Competition Law and Economics, 2-3, 349-474. Disponible en: https://doi.org/10.1093/joclec/nhl016.

Sluijs, J. P. (2010). Network Neutrality Between Falses Positives and Falses Negatives: Introducing a European Approach to American Broadban Markets. Federal Communications Law Journal, 62 (1), 77-117.

UNESCO (2015). Principles for governing the Internet. A comparative analysis. UNESCO Series on Internet Freedom. Disponible en: https://bit.ly/2Mg0p2G.

Wu, T. (2004). The Broadband Debate, A User's Guide. Journal of Telecommunications and High Technology Law, 3, 69. Disponible en: https://bit.ly/2QCFMfS. (2005). Network Discrimination, Broadband Discrimination. Journal of Telecommunications and High Technology Law, 4, 141-179.

Wu, T. y Lessig, L. (2003), Letter to the FCC. Disponible en: https://bit.ly/2W5DdE6.

Wu, T. y Yoo, C. S. (2007). Keeping the Internet Neutral?: Tim Wu and Christopher Yoo Debate. Faculty Scholarship. Paper 779. Disponible en: https://bit.ly/30YvHP2.

Yemini, M. (2008). Mandated Network Neutrality and the First Amendment: Lessons fron Turner and a New Approach. Virginia Journal of Law \& Techno$\log y, 13(1), 1-45$.

Yoo, C. S. (2005). Beyond Network Neutrality. Harvard Journal of Law \& Technology, 19 (1), 1-77. Disponible en: https://bit.ly/2JLWxEB.

Zhu, Z. (2007). Bringing Neutrality to Network Neutrality. Berkeley Technology Law Journal. 22 (1), 615-645. Disponible en: https://bit.ly/2JN5RYU. 